\title{
An exploration of frictional and vibrational behaviors of textured deep groove ball bearing in the vicinity of requisite minimum load
}

\author{
K. E. Ch. VIDYASAGAR ${ }^{1,2}$, R. K. PANDEY ${ }^{3}$, Dinesh KALYANASUNDARAM ${ }^{1,4, *}$ \\ ${ }^{1}$ Center for Biomedical Engineering, Indian Institute of Technology Delhi, New Delhi 110016, India \\ ${ }^{2}$ Department of Biomedical Engineering, College of Engineering, Osmania University, Telangana 500007, India \\ ${ }^{3}$ Department of Mechanical Engineering, Indian Institute of Technology Delhi, New Delhi 110016, India \\ ${ }^{4}$ Department of Biomedical Engineering, Indian Institute of Technology Delhi, New Delhi 110016, India \\ Received: 28 August 2020 / Revised: 23 December 2020 / Accepted: 22 January 2021 \\ (C) The author(s) 2021.
}

\begin{abstract}
In case of lightly loaded radial ball bearings, failure mechanisms other than fatigue such as smearing of raceways due to increased frictional torque and vibrations often prevail. Hence, attempts have been made herein for reducing the frictional torque and minimizing the vibrations of a radial deep groove ball bearing employing surface textures at the inner race. Nanosecond pulsed laser was used to create texture (involving micro-dimples having different dimple area density) on the inner race of test bearings. Using an in-house developed test rig, frictional torque and vibrational parameters were measured at different speeds and light loads (i.e. in vicinity of $0.01 C$, where $C$ is dynamic load capacity of radial ball bearing). Significant reduction in frictional torque and overall vibrations were found in the presence of micro-dimples on inner race at light loads irrespective of operating speeds. Even without satisfying the minimum load needed criteria for the satisfactory operation, substantial reduction in smearing marks was found on the races of textured ball bearings in comparison to conventional cases.
\end{abstract}

Keywords: ball bearing; textured inner race; grease lubricated; frictional torque; vibration

\section{Introduction}

Grease lubricated deep groove ball bearings are widely employed in machines and mechanical systems in industries due to involved simplicity in lubrication. However, these bearings possess low inherent damping capacity due to poor retain-ability of grease/lubricant at the concentrated contacts of balls/races. This makes radial ball bearings energy inefficient and prone to vibrations. Figures 1(a) and 1(b) show the photographic views of an assembled radial ball bearing and its components, respectively. However, Figs. 1(c) to 1(f) illustrate the mechanism of grease removal from the track when a ball was moved on the inner race. This explanation demonstrates that how scarcity of grease prevails in practical situations resulting in starved lubricated bearings. Several authors have reported their studies involving the starved lubrication and have found adverse behaviours of it on bearings/ contacts [1-9]. In the past several decades, research groups globally have made attempts to improve the effective lubrication in the rolling bearings in spite of lubricant scarcity [10]. Various techniques such as new designs of cage, new materials of cage, surface coatings, and blending of nanoparticles/additives in the lubricants have been employed to improve the performances of rolling bearings and generic concentrated contacts [11-19].

In recent past years, surface textures involving certain type of patterning of nano/micro geometries have

* Corresponding author: Dinesh KALYANASUNDARAM, E-mail: dineshk.iitdelhi@gmail.com 

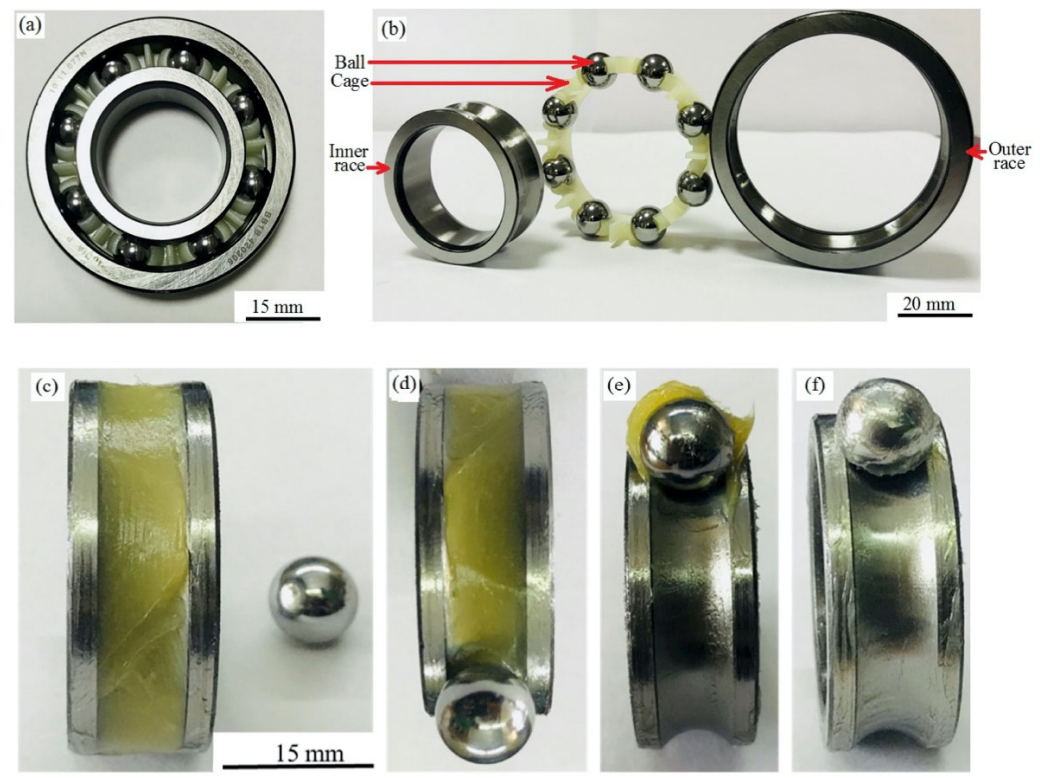

Fig. 1 Photographic views of a radial deep groove ball bearing and pushing aside of grease employed in lubrication. (a) Assembled ball bearing; (b) components of ball bearing; (c) grease filled track on inner raceway; (d) one ball positioned on track at inner raceway; (e) removal of grease from raceway when a ball moves; (f) track view of inner raceway after few passes of a ball.

emerged as a viable technology to improve the tribodynamic behaviors of lubricated generic concentrated contacts as well as contacts found in the machine elements [20-22]. Based on the numerical [23-32] and experimental [33-41] investigations on lubricated textured concentrated contacts under unidirectional motion, researchers have reported vital beneficial results in terms of reduction in friction coefficient/frictional torque and decrease in temperature rise. Moreover, substantial reduction in the vibration and noise have also been reported at the lubricated textured contacts for wide range of operating parameters [20, 23]. It has been established that texture attributes such as shape, size, and orientation of tiny geometries play significant role in the effective lubrication at the concentrated contacts. Micro-features/dimples of dimensions smaller than the Hertzian contact size have yielded better tribodynamic performances. Researchers have experimentally investigated the role of surface textures on lubricated reciprocating/oscillating contacts. A decrease in the overall vibrations and reduction in friction coefficient have been reported at the lubricated textured concentrated contacts in comparison to conventional reciprocating/ oscillating contacts [42-45].

Effects of surface textures/dents on the fatigue life of heavily loaded concentrated contacts have been explored using numerical and experimental approaches
[36, 46-53]. Broadly it has been concluded that enhancement in fatigue life has occurred due to improved lubrication in the presence of oil filled tiny dimples present in surface textures. Presence of dimples/dents yielded longer pitting durability and prevented the scuffing at higher contact loads [48, 49]. Extended durations of experimental studies were conducted to explore the influence of surface textures on the fatigue life of hardened steel surfaces under heavily loaded rolling/sliding motions [36, 47, 50-53]. It has been observed that deep dents (greater than $20 \mu \mathrm{m}$ depth) caused detrimental effects on fatigue life, whereas the presence of shallow dimples of depth $<1.0 \mu \mathrm{m}$ have increased the fatigue life even at high loads [53].

It is understood based on the information provided in the literature that the ball bearings must be operated with a requisite minimum load $(>0.02 C$, where $C$ is dynamic load capacity corresponding to each bearing) in order to achieve the satisfactory operation. If the requisite minimum load is not applied then the tribological and dynamic performances of the rolling bearings deteriorate due to the skidding of balls at the raceways that yield high frictional torque and large magnitude vibrations. Moreover, it is also found based on the literature review that certain surface textures are beneficial in terms of reducing the friction and vibration at lubricated concentrated contacts. Thus, 
idea came in mind of authors to explore the effect of surface texture on frictional, vibrational, and smearing marks (on raceways) of a radial deep groove ball bearing operating at the loads in the vicinity to the requisite minimum load. Hence, objective of this work was set to experimentally explore the effect of a textured ball bearing (with textured inner race) on frictional, vibrational, and smearing marks (on raceways) in comparison to conventional (without textured inner races) bearing at light loaded conditions. The radial deep groove ball bearing of designation SKF-BB1B 420206 was employed in this experimental study due to their ease (without inception of any defects) in component's disassembly and assembly for/after texturing over the inner race.

\section{Experimental methods and materials}

\subsection{Details of sample ball bearing and texturing}

SKF make radial deep groove ball bearings (BB1B 420206) were employed in this study, whose inner race, outer race, and rolling elements (balls) were made of bearing steel (EN31) while the cage was made of polyamide material. All the sample ball bearings were procured from the same manufacturing batch. This particular bearing was chosen due to the associated ease of disassembly/ reassembly of its components without causing any surface damages. The polyamide cage was designed with a snap-type fit that helped in the disassembly and reassembly of bearing components as photographically illustrated in Figs. 2(a)-2(p). The surface of the inner-race was micro-textured using a nanosecond pulsed fiber laser that delivered up to $50 \mathrm{~W}$ of average laser power at 1,064 $\mathrm{nm}$ wavelength, with a repetition rate ranging between 25 to $500 \mathrm{kHz}$. Semi-spherical micro-geometries/dimples were textured on the inner race of the bearings with an average diameter of dimples ranging in $28 \pm 4 \mu \mathrm{m}$. The patterns of the micro-dimples created on the inner race of test bearings have been schematically illustrated in Fig. 3. The textures having dimple area densities (DAD) of $5 \%, 15 \%$, and $25 \%$ were manufactured for explorations. The texture area density is the ratio of the surface area ablated by laser divided by total area i.e. [(number of dimples $x$ area of each dimple) / total area]. The total
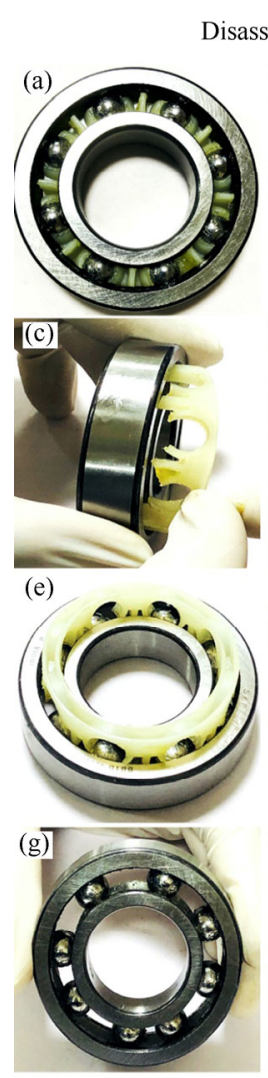

Disassembly

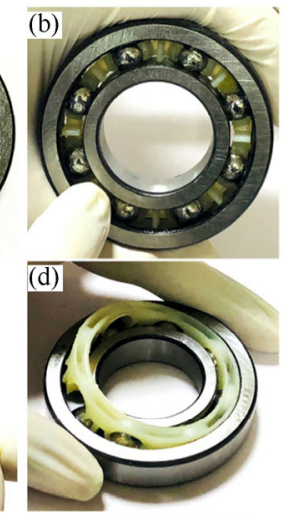

(f)
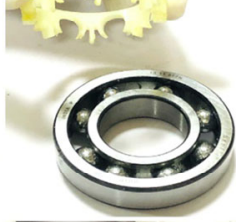

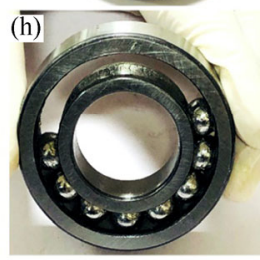

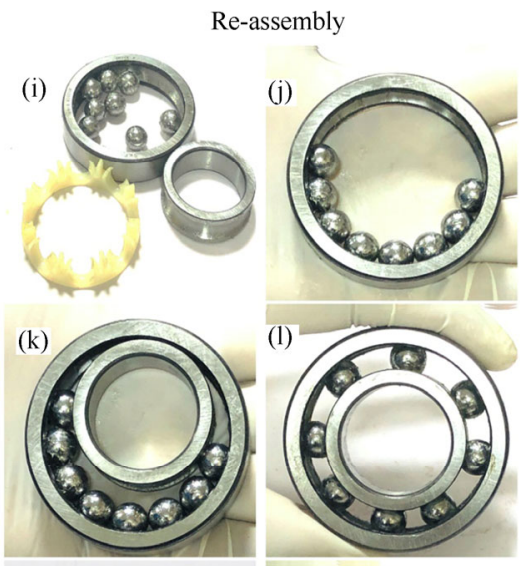

(m)

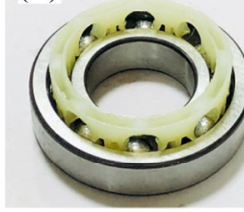

(o)

(n)

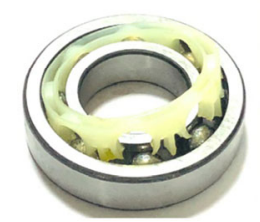

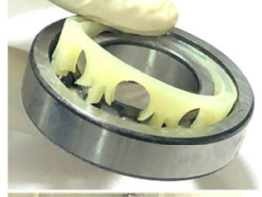

(p)

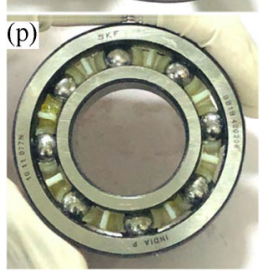

Fig. 2 Photographic illustration of disassembly (a) to (h) and reassembly (i) to (p) of a test ball bearing. 

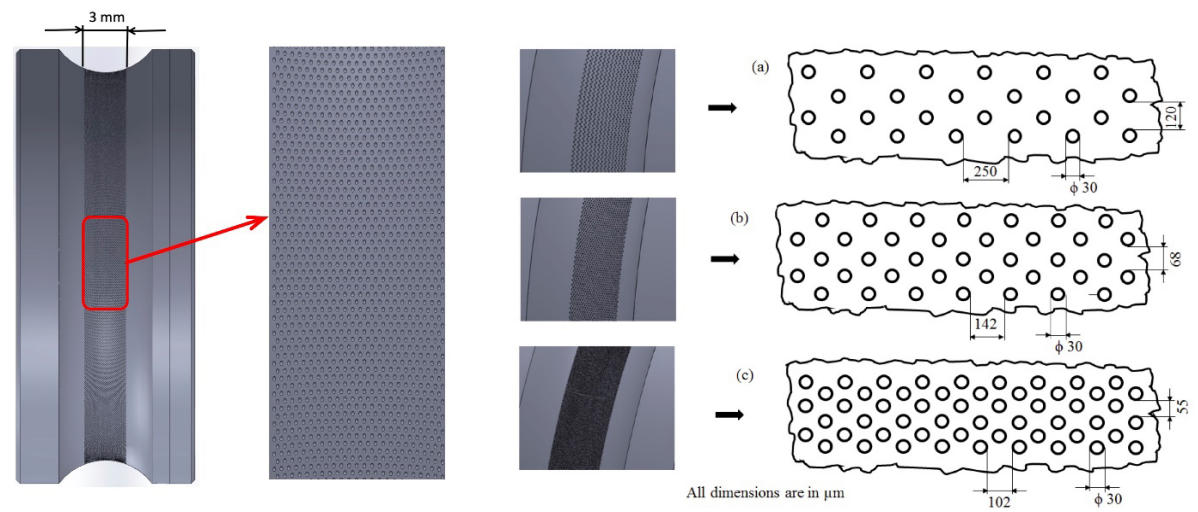

Fig. 3 Schematic illustration of textured surface and micro-dimple patterns on inner raceways. (a) With 5\% dimple area density; (b) with $15 \%$ dimple area density; and (c) with $25 \%$ dimple area density.

dimples are evenly distributed on the race surface. The optimized laser parameters employed for the surface texturing and the other related details are listed in Table 1 . The scanning electron microscope (SEM) images of textured and lapped-textured inner races were captured as shown in Figs. 4(a)-4(c) corresponding to $5 \%, 15 \%$, and $25 \% \mathrm{DAD}$. It is worth noting here that the surface roughness $\left(R_{a}\right)$ of conventional (fresh untextured pieces) and textured (pieces after lapping) inner races of test bearings were measured and found in the range of $0.08-0.09 \mu \mathrm{m}$.

\subsection{Test rig and experimental aspects}

A test rig was designed and developed for conducting the experiments on test bearings (radial deep groove ball bearings). Frictional torque and vibrational amplitude parameters were measured in-situ using an S-type load cell and two proximity probes, respectively. Figures 5(a) and 5(b) show a CAD model

Table 1 Laser parameters and micro-texture details.

\begin{tabular}{lc}
\hline \multicolumn{1}{c}{ Type of laser } & Fiber laser \\
\hline Mode of operation & Pulsed \\
Wavelength $(\mathrm{nm})$ & 1,064 \\
Frequency $(\mathrm{kHz})$ & 150 \\
Average power $(\mathrm{W})$ & 17.5 \\
Marking speed $(\mathrm{mm} / \mathrm{s})$ & 100 \\
Pulse width $(\mathrm{ns})$ & 2 \\
Fluence $\left(\mathrm{J} / \mathrm{cm}^{2}\right)$ & 16.5 \\
Dimple depth $(\mu \mathrm{m})$ & $15 \pm 3$ \\
Dimple diameter $(\mu \mathrm{m})$ & $28 \pm 4$ \\
Dimple area density $(\%)$ & $5,15,25$ \\
\hline
\end{tabular}

(a) Textured inner race with $5 \%$ dimple area density

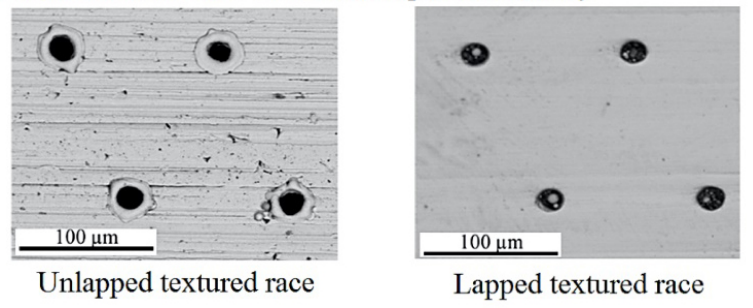

(b) Textured inner race with $15 \%$ dimple area density
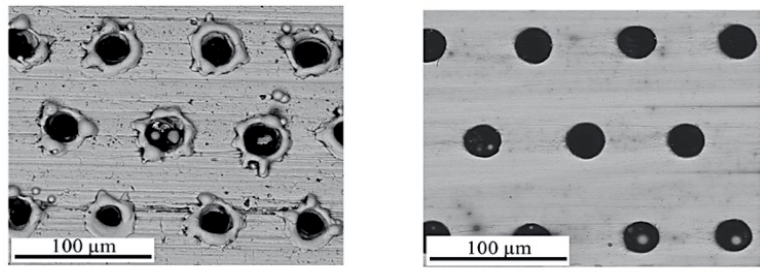

Unlapped textured race

Lapped textured race

(c) Textured inner race with $25 \%$ dimple area density

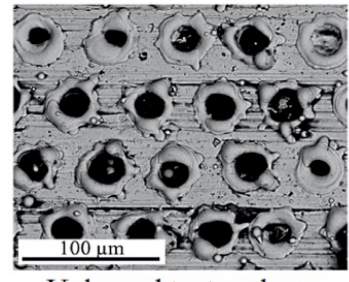

Unlapped textured race

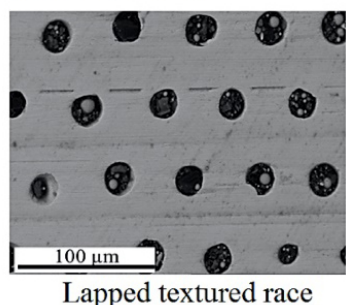

Lapped textured race
Fig. 4 SEM images of inner races after micro-texturing and after lapping. (a) With 5\% dimple area density; (b) with $15 \%$ dimple area density; and (c) with $25 \%$ dimple area density.

and a photographic view of the test rig, respectively. The DC electric motor and test bearing mounted shafts were connected using a jaw coupling to minimize the transmission of vibrations and heat flow towards the test bearing. The rotational speed was controlled by a DC motor controller. The inner races of the test bearings were press-fitted to the shaft while the outer 


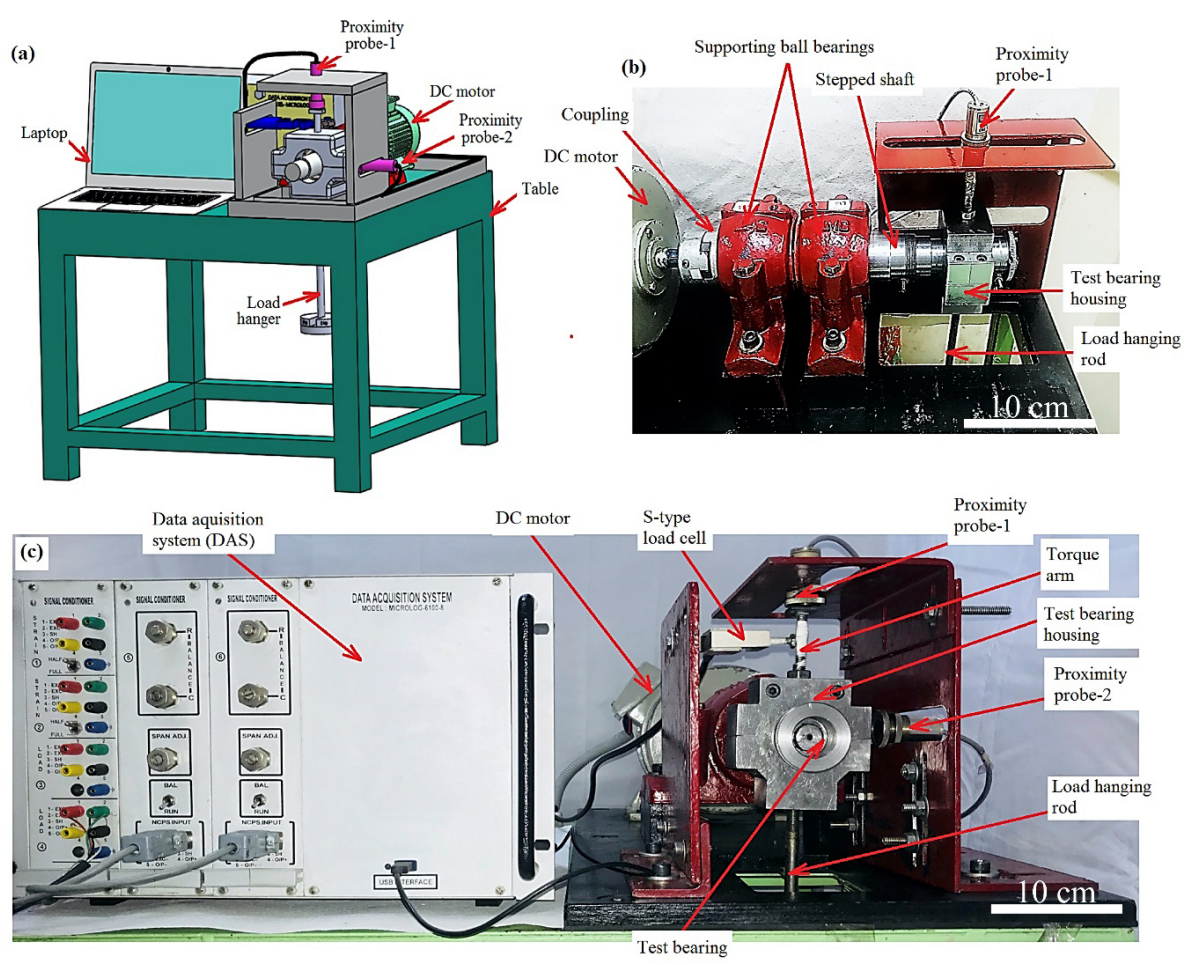

Fig. 5 Details of experimental set-up. (a) 3D CAD model of test rig; (b) photographic view (view-1) of test rig with names of components; and (c) data acquisition system (DAS) with photographic view (view-2) of test rig with names of components.

races were held stationary in a floating housing. The bearing housing rotation was arrested using the S-type load cell for measuring the frictional torque. The vibrational displacements during rotation were measured in vertical and horizontal directions using two proximity sensors. The load cell and proximity sensors were calibrated before each set of experiments. The output from the proximity sensors were in $\mathrm{mV}$. Load cell and proximity sensors were connected to a data acquisition system (DAQ) as can be seen in Fig. 5(c). A laptop connected to the DAQ was used for recording the data during the experiments. The raw data of vibrational amplitude as a function of time is obtained from the sensor. The displacement from voltage output was mapped to enable the measurement of vibrational amplitude. Fast Fourier transform (FFT) was applied to the collected vibrational data to evaluate the vibrational magnitudes as function of frequency.

Commercially available general-purpose grease was used for lubrication of test bearings. The properties of the grease are listed in Table 2. Steady state (i.e. constant temperature at outer race) has been arrived for all sets of operating conditions before recording the results. Depending on the values of input data, steady state temperature reached after lapse of time varying in the range of 30 to $60 \mathrm{~min}$. Based on this observation, it was decided to conduct each experiment for duration of $60 \mathrm{~min}$. The operating parameters are also listed in Table 3. Reaching of steady state temperature has been shown in Figs. 6(a) and 6(b) for the cases of bearings having conventional and textured inner races, respectively, at a set of operating parameter.

Table 2 Properties of grease.

\begin{tabular}{cc}
\hline Soap & Lithium \\
\hline Base oil & Mineral oil \\
Base oil viscosity at $40^{\circ} \mathrm{C}\left(\mathrm{mm}^{2} / \mathrm{s}\right)$ & $120-130$ \\
Base oil viscosity at $100^{\circ} \mathrm{C}\left(\mathrm{mm}^{2} / \mathrm{s}\right)$ & $12-13$ \\
National lubricating grease institute (NLGI) grade & 3 \\
Penetrations number $\left(10^{-1} \mathrm{~mm}\right)$ & $220-280$ \\
\hline
\end{tabular}

Table 3 Operating parameters.

\begin{tabular}{cc}
\hline Operating parameter & Value \\
\hline Load $(\mathrm{N})$ & $20,40,60$ \\
Hertzian pressure $P_{\mathrm{H}}(\mathrm{GPa})$ & $1.2,1.6,1.9$ \\
Speed $(\mathrm{rpm})$ & $500 ; 800 ; 1,100 ; 1,400$ \\
Speed $(\mathrm{m} / \mathrm{s})$ & $1.2,2.0,2.5,3.4$ \\
\hline
\end{tabular}



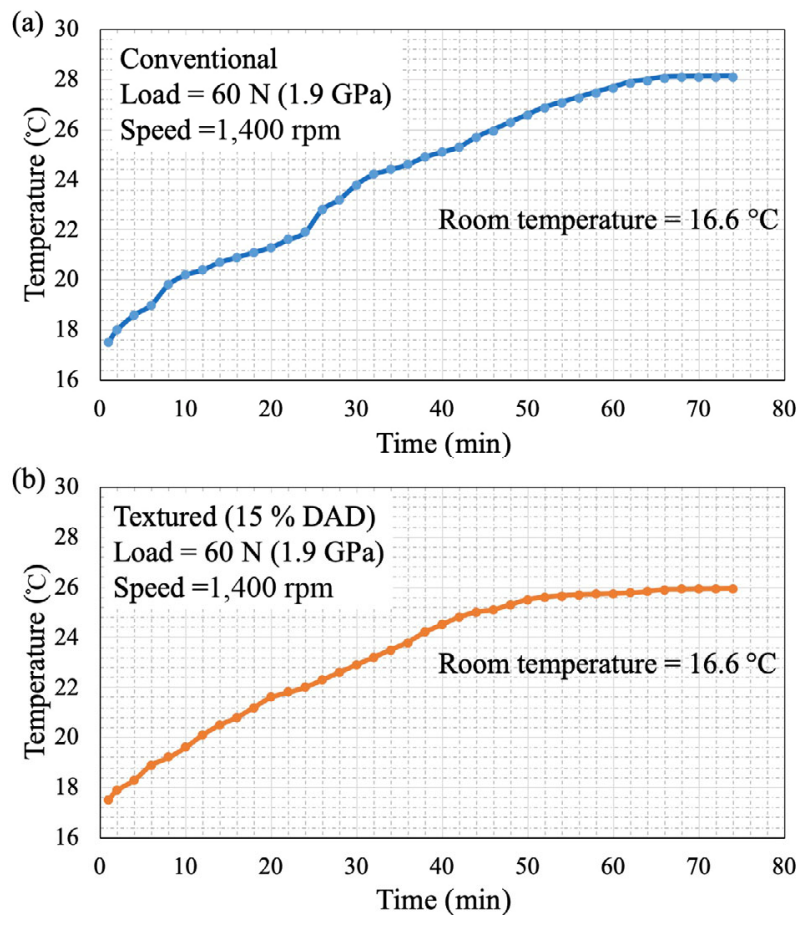

Fig. 6 Temperature variation at outer race of two test bearings with time while achieving the steady state condition. (a) Conventional inner race and (b) textured inner race.

It is worth reporting here that before start of each experiment, the components and test bearings were ultrasonically cleaned using propanol followed by drying at room temperature. Well before start of experiment, each test bearing was lubricated using $2 \mathrm{~g}$ of grease. Thereafter, the frictional torque and vibrations were recorded for analysis/interpretation after reaching to steady state condition of bearing (i.e. outer race reaching to a constant temperature).

\section{Results and discussion}

\subsection{Frictional torque}

The measured values of the frictional torque with conventional (without textured inner race) and textured bearings (with textured inner race having different DAD) at different operating parameters are shown in Fig. 7. The substantial reduction in the frictional torque can be observed with textured bearings as compared to conventional. The textured bearings with $5 \% \mathrm{DAD}$ have yielded reduction in frictional torque in the range of $5 \%-35 \%$ in comparison to conventional case. However with $15 \%$ DAD, the minimum and the maximum reductions in the frictional torque values with respect to the conventional are found around $13 \%$ and $47 \%$, respectively. At higher DAD (25\%), the minimum and maximum frictional torques reduction have been recorded around $6 \%$ and $40 \%$, respectively. In light of these observations, the textured bearing having $15 \%$ DAD is found best performing from the reduction in frictional torque perspective. For exploring the reasons behind this performance improvement, after finishing the experiments at a set of operating parameter $($ Load $=60 \mathrm{~N}$, Speed $=1,400 \mathrm{rpm})$, the SEM investigation of textured and conventional inner races were performed. The captured SEM micro-images have been shown in Figs. 8(a)-8(d). In these images, it can be seen that inner races of conventional (Fig. 8(a)) and textured (with 25\% DAD, Fig. 8(d)) bearings got severely damaged than the cases of $5 \%$ (Fig. 8(b)) and 15\% (Fig. 8(c)) DADs. This has been

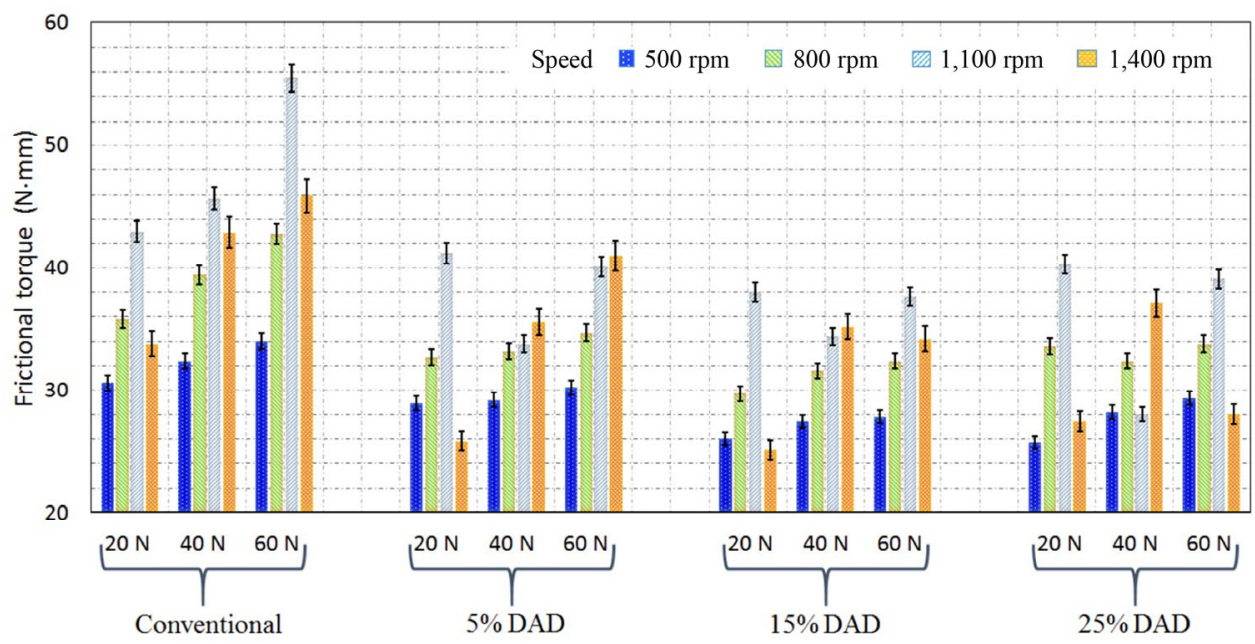

Fig. 7 Frictional torque of conventional and textured inner races test ball bearings at different operating parameters. 
(a) Conventional

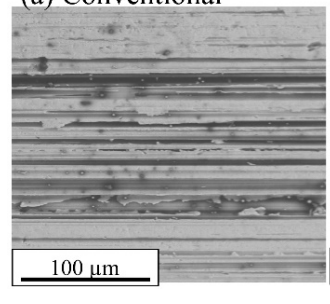

(b) $\mathrm{DAD}=5 \%$

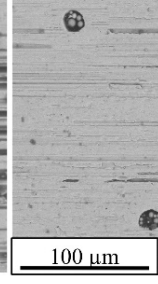

(c) $\mathrm{DAD}=15 \%$

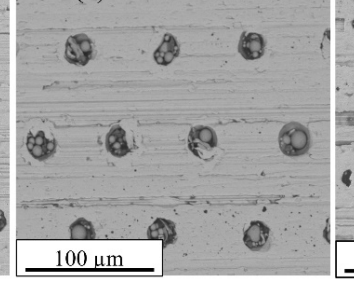

(d) $\mathrm{DAD}=25 \%$

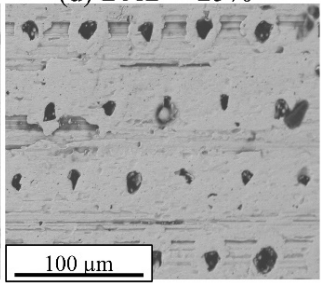

Fig. 8 SEM images of inner races of conventional and textured inner races after the experiments (operating parameters: load $=60 \mathrm{~N}$, speed $=1,400 \mathrm{rpm})$.

interpreted as more physical contacts (asperity-toasperity contacts) have taken place between balls and inner races in the cases of conventional and 25\% DAD. Large number of asperity-to-asperity contacts yielded deep smearing/scratch marks (Fig. 8(a)) on conventional race surface resulting in high frictional torque. However in case of $25 \%$ DAD (Fig. 8(d)), pitting marks and filling/damage of dimples on inner race are visible. This indicates that it has happened due to increase in contact stress and deterioration in effective lubrication at ball/race interface. Increase in stress at the contact has happened due to removal of relatively more surface area in case of $25 \%$ DAD. Moreover, it is understood that best results with DAD of $15 \%$ has occurred due to improvement in the lubrication mechanisms as explained in Figs. 9(a)-9(c). In presence of texture on inner race, mainly three modes of lubrication at the interfaces of balls/race were expected as schematically explained in Fig. 9. The pair of dimpled surface (inner race) and running counter surface (balls) might have formed innumerable micro-fluid film bearings (Fig. 9(a)). The pressure generated at innumerable locations in tiny fluid film bearings might have supported the loaded body over the thin film. In this way, the physical contacts between the balls and textured race might have got avoided (or reduced) resulting in reduction of frictional torque. The dimples also might have acted as innumerable micro-oil reservoirs and debris/contaminants trappers, which must have provided the oil for smearing at the interface in case of severe mixed lubrication or/and in presence of scarcity of oil. These mechanisms have been schematically explained in Figs. 9(b) and 9(c). Cumulatively, the micro-textured surfaces have played vital role in improving the performance behaviors of the ball bearings.

The comparison of SEM micrographs in Figs. 10(a)

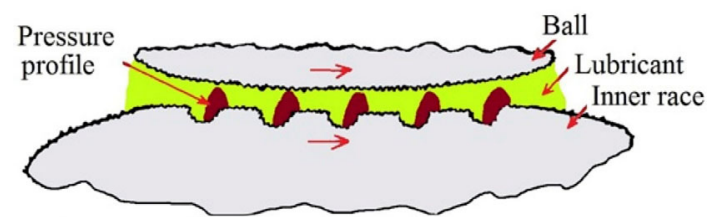

(a) Innumerable micro-hydrodynamic bearings

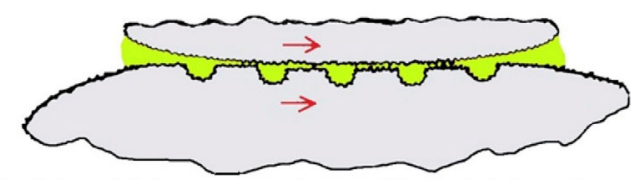

(b) Micro lubricant reservoirs provide the lubricant for smearing at the interface in mixed/starved lubrication conditions

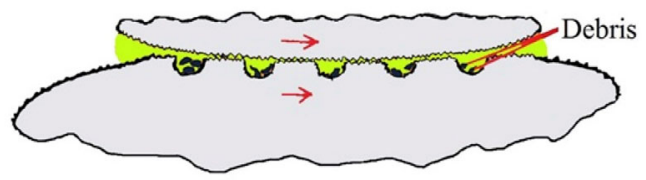

(c) Contaminant/debris trappers

Fig. 9 Mechanisms responsible for lubrication improvement in presence of texture.

and 10(b) reveals presence of severe scratches on the balls of conventional bearing as compared to the textured case. This observation also indirectly indicates that film thickness of lubricating oil has improved in presence of texture, which caused lesser asperity to asperity interactions, thus, less scratch marks on the balls of textured bearing. It is worth noting here that the texture has resulted in better retainability of oil at the inner race, which has improved the lubrication and accordingly enhancement in the performance behaviors as compared to conventional case. The retainability of lubricant at the textured inner race has also been observed based on the photographic evidence of inner race after conducting an experiment. Figures 11(a) and 11(b) show the photographic images of conventional and textured inner races, respectively. Figure 11(b) reveals better oil/grease retainability in presence of texture. The oil adherence on inner races 
has also been ascertained in terms of the contact angle measured using the Goniometer. Figures 12(a) and 12(b) demonstrate the contact angles measured between oil (base oil of grease) droplet and races before and after the tests. In cases of textured race (Fig. 12(b)), contact angle has substantially been found less than conventional case. This also supports the better retainability of lubricant at texture race. The transmission

(a) SEM images of a ball of conventional bearing at three different locations

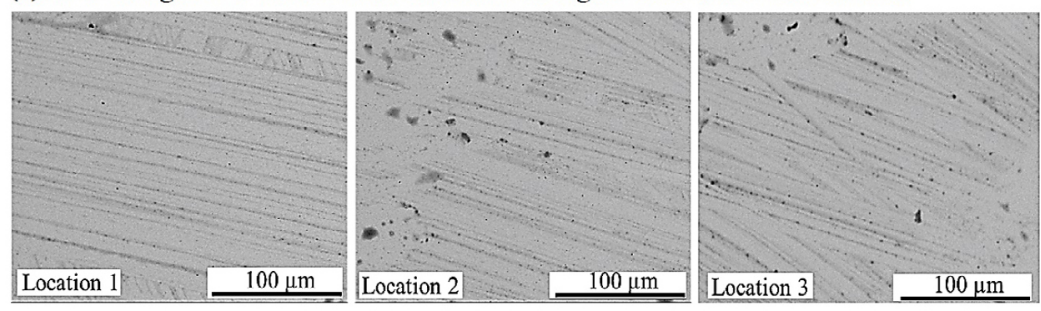

(b) SEM images of a ball of textured bearing at three different locations $(\mathrm{DAD}=15 \%)$

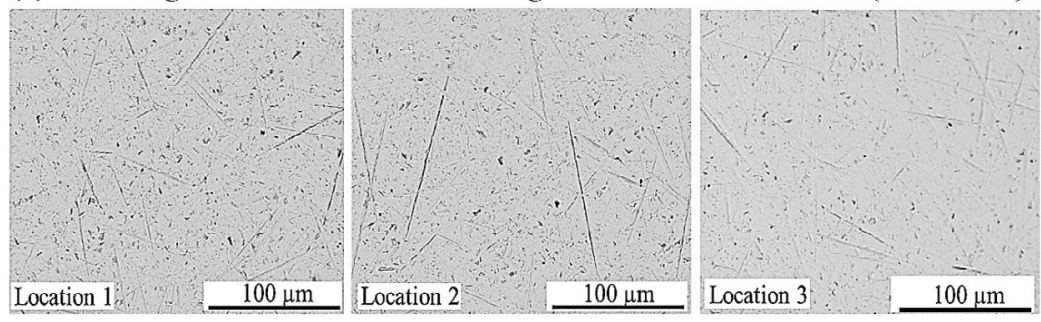

Fig. 10 SEM images of balls of test bearings (operating parameter: load $=60 \mathrm{~N}$, speed $=1,400 \mathrm{rpm}$ ).

(a)

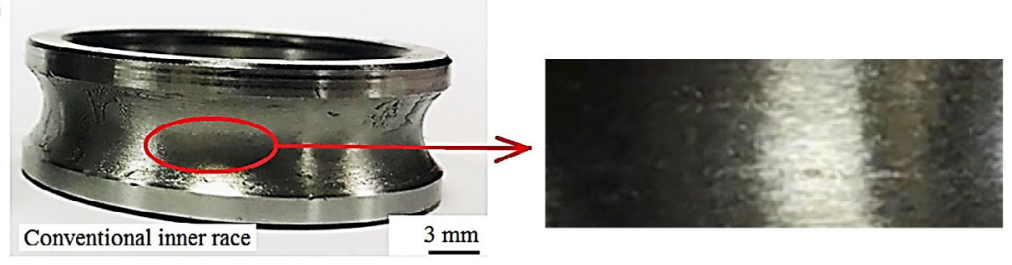

(b)

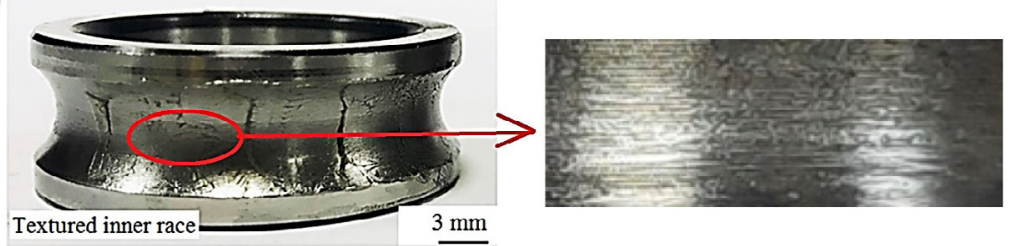

Fig. 11 Photographic view of inner races after the experiment (load $=60 \mathrm{~N}$, speed $=1,400 \mathrm{rpm}(3.4 \mathrm{~m} / \mathrm{s})$, DAD = 15\%). (a) Visual of inner race (conventional bearing) and (b) visual of textured inner race (textured bearing).

(a)

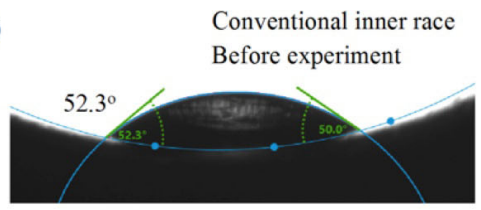

(b)

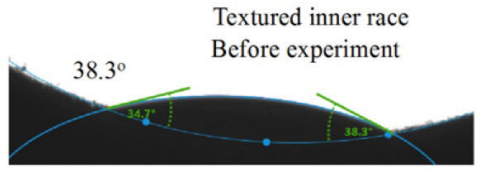

Conventional inner race After experiment
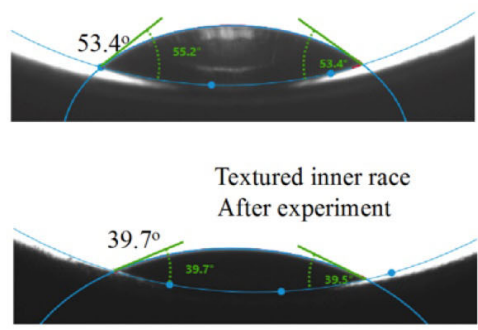

Fig. 12 Contact angle between the oil droplet and inner race. (a) Conventional race and (b) textured race. 
electron microscopy (TEM) images of fresh and used greases are shown in Figs. 13(a)-13(c). It can be seen in these figures that relatively less damage of grease's soap fibers has taken place in presence of texture. This indicates increase in grease life with textured bearing. Moreover, the mechanical efficiency of the test bearings at a set of operating parameters was measured. It was found that the efficiency of conventional bearing varied in the range of $96 \%$ to $97 \%$ at the load of $60 \mathrm{~N}$ and speed of 1,400 rpm. However with textured bearing, the efficiency was measured always above $98 \%$.

\subsection{Vibrations}

In order to compress the paper, this section presents only vertical vibration results for the cases of conventional and textured ball bearings measured at different operating parameters. Based on the vibrational analysis in the frequency domain, the amplitudes of the vibrations obtained at combinations of operating parameters (loads and speeds) have been presented in Fig. 14. It can be observed in this figure that vibrations have substantially reduced in the presence of micro-textures on inner race of bearings. This finding indicates towards increase in the damping due to improved film formation at the interfaces of inner race and balls in case of textured bearing. It is worth mentioning here that all the vibration results presented in this section belong to the best performing textured test bearing i.e. with 15\% DAD. The vibration responses of conventional and textured ball bearings at operating loads $(20 \mathrm{~N}(1.2 \mathrm{GPa}), 60 \mathrm{~N}(1.9 \mathrm{GPa}))$ and speed (500 rpm $(1.2 \mathrm{~m} / \mathrm{s})$ ) have been presented in time and frequency domains in Figs. 15 and 16, respectively. Overall reduction in the vibration amplitudes in the presence of textured inner race in comparison to conventional case can be seen in time domain in Fig. 15 irrespective of load applied on the test bearings. However in the frequency domain in Fig. 16, about $46 \%$ and $25 \%$ reductions in vibrational magnitude in the presence of texture are found at rotational frequency of $8.4 \mathrm{~Hz}$ and at the loads of $20 \mathrm{~N}$ (1.2 GPa) and $60 \mathrm{~N}$ (1.9 GPa), respectively. The results embodied
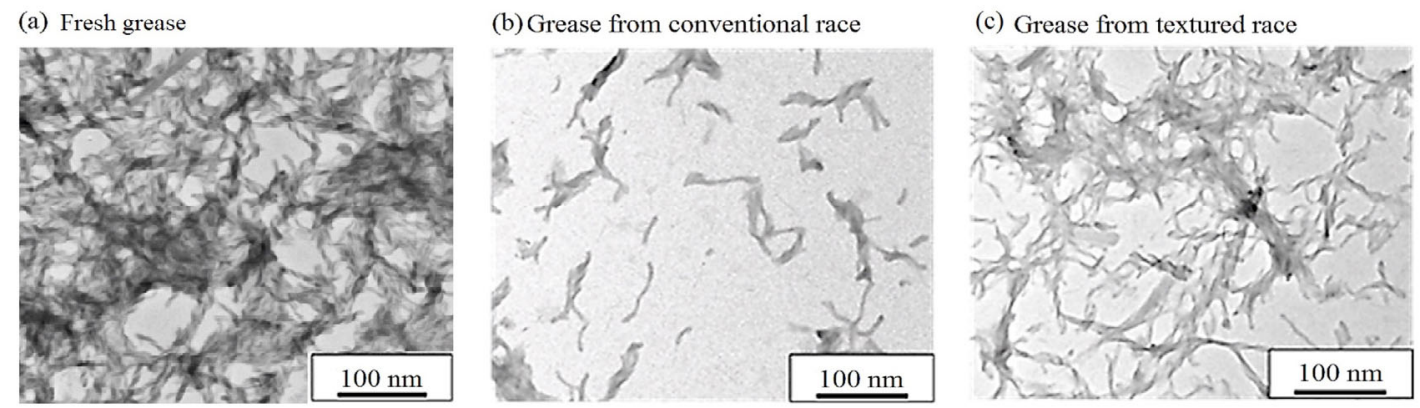

Fig. 13 TEM images of micro-textured surfaces of inner races after the experiments (operating parameter: load $=60 \mathrm{~N}$, speed $=$ $1,400 \mathrm{rpm})$.

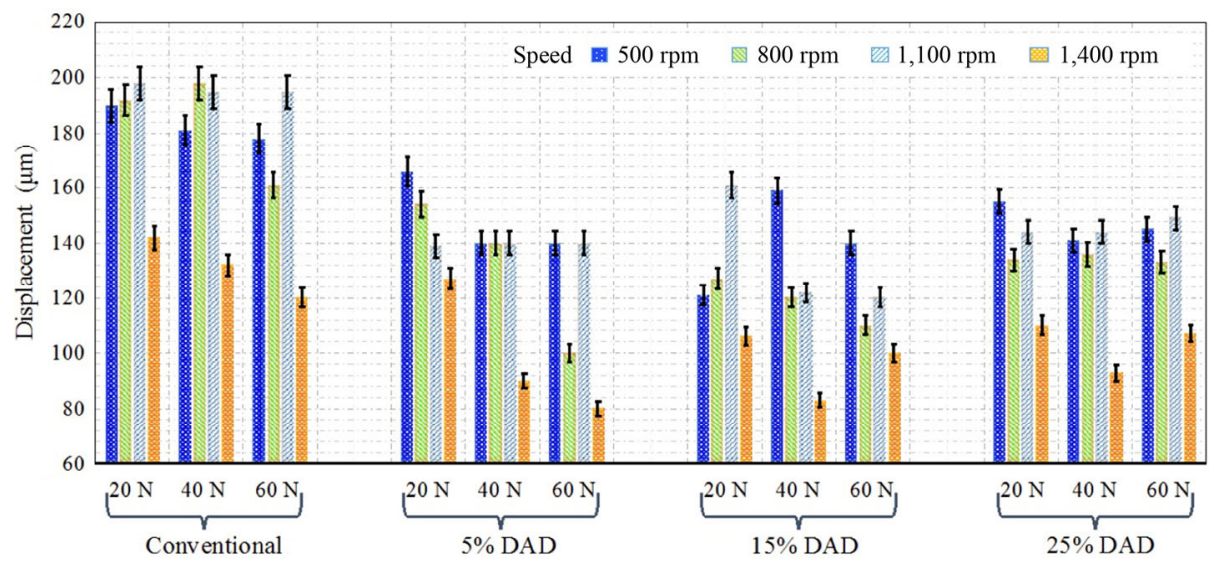

Fig. 14 Comparisons of vibration amplitudes at rotational frequencies for conventional and micro-textured races test bearings. 

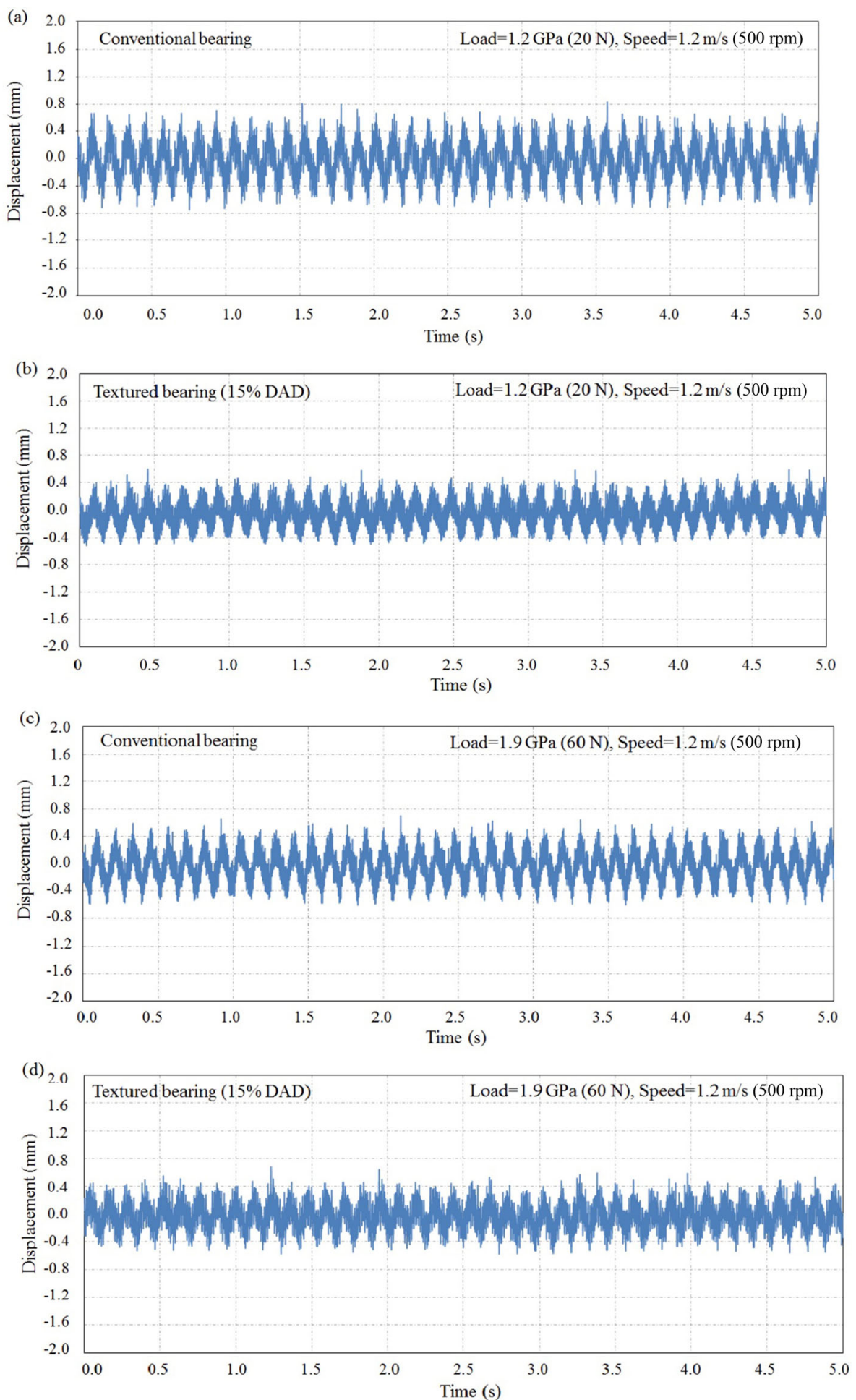

Fig. 15 Comparisons of vibrations of conventional and micro-textured races ball bearings in time domain at two different loads and $500 \mathrm{rpm}(1.2 \mathrm{~m} / \mathrm{s}$ speed $)$.

in Figs. 17 and 18 at relatively high speed (i.e. 1,100 rpm $(2.5 \mathrm{~m} / \mathrm{s}))$ yield larger reduction in the overall vibrations with textured bearings. It is understood that this had occurred as a result of better lubricating film formation at high speed (1,100 rpm) as compared to low speed (500 rpm). The vibration amplitudes at different harmonics have also been summarized in Table 4 for the cases of conventional and textured bearings for 

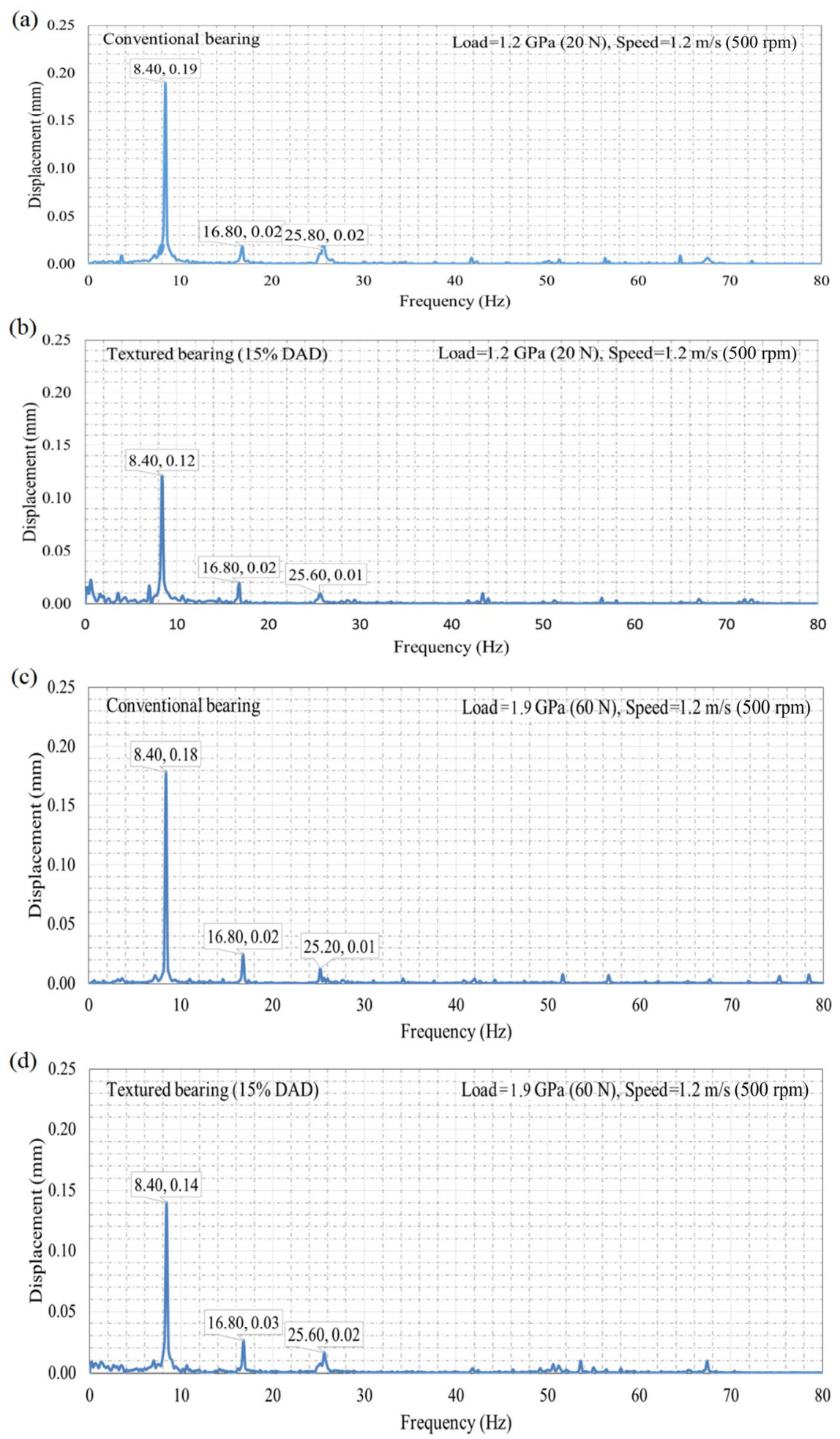

Fig. 16 Comparisons of vibrations of conventional and micro-textured races ball bearings in frequency domain at two different loads and $500 \mathrm{rpm}(1.2 \mathrm{~m} / \mathrm{s}$ speed).

ease in comparison from readers' perspective. Table 4 indicates the reduction of vibrations even at the harmonics with textured bearings.

\section{Conclusions}

Based on the experimental tribo-dynamic investigations 

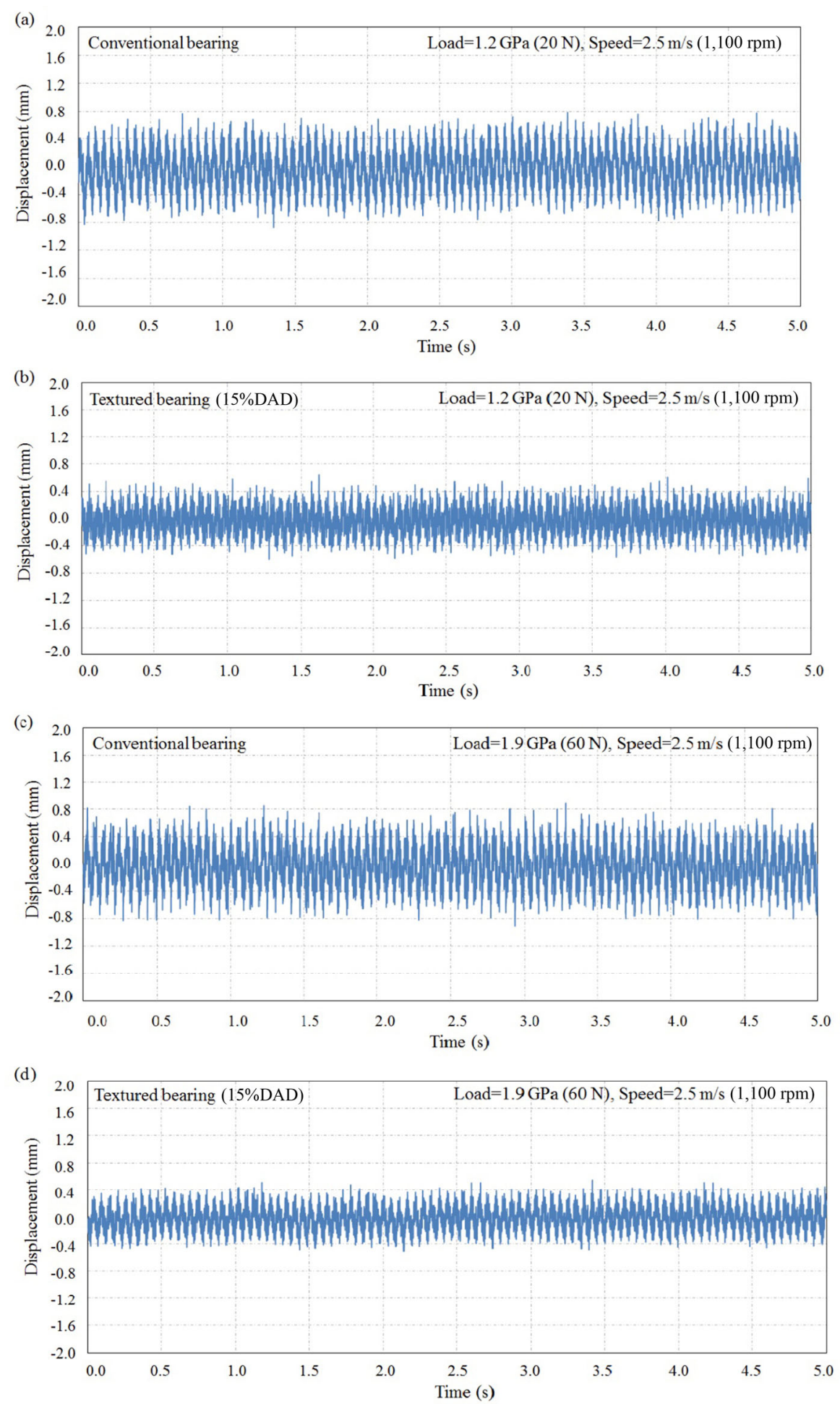

Fig. 17 Comparisons of vibrations of conventional and micro-textured races ball bearings in time domain at two different loads and $1,100 \mathrm{rpm}(2.5 \mathrm{~m} / \mathrm{s}$ speed$)$.

of conventional and textured ball bearings presented in this paper, the following conclusions have been drawn:

1) Significant reduction ( $15 \%$ to $47 \%$ ) in the frictional torque have been found with textured bearing in comparison to conventional case.

2) Vibration amplitudes have reduced substantially in the range of $25 \%$ to $46 \%$ in the presence of texture 

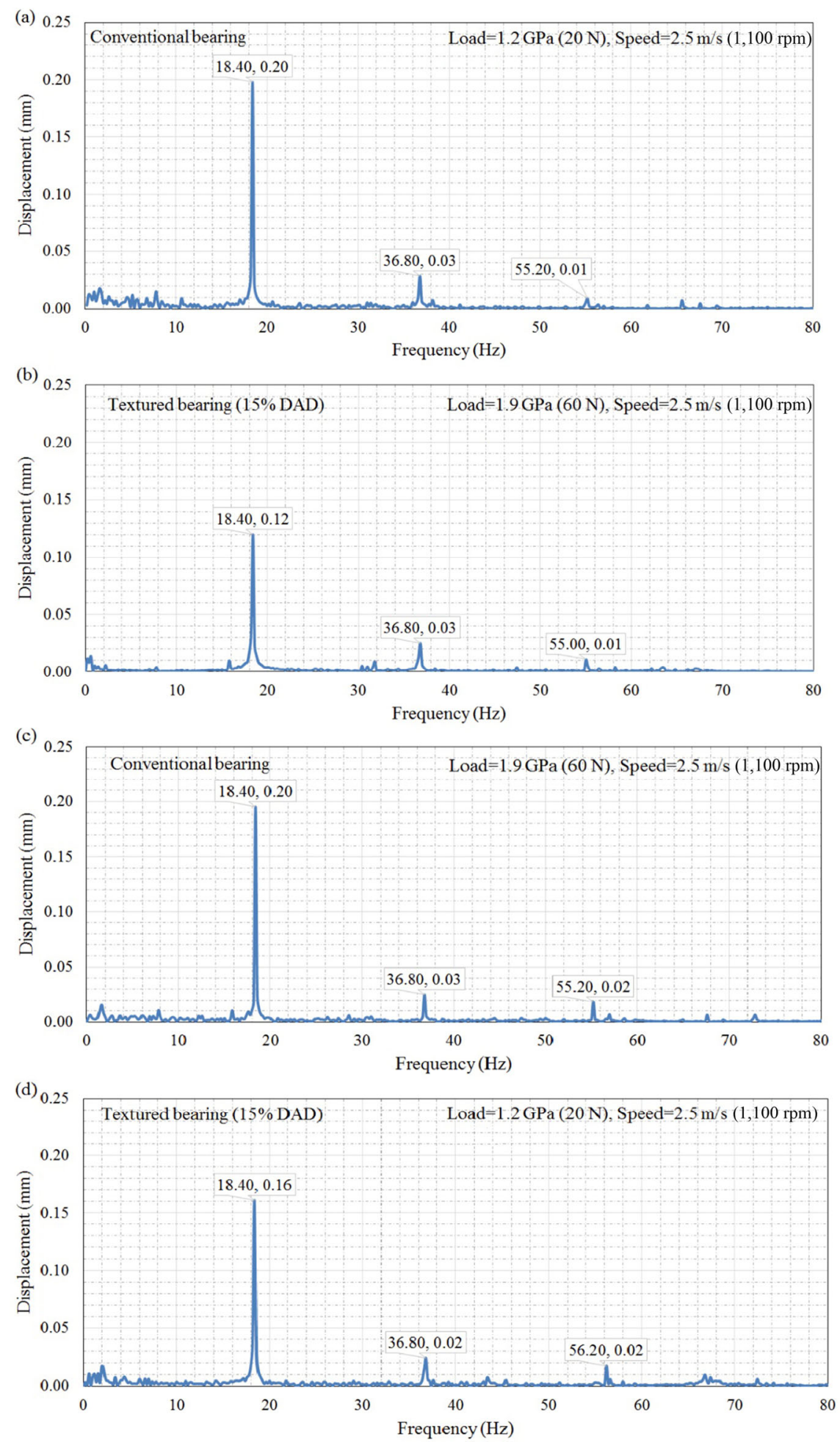

Fig. 18 Comparisons of vibrations of conventional and micro-textured races ball bearings in frequency domain at two different loads and $1,100 \mathrm{rpm}(2.5 \mathrm{~m} / \mathrm{s}$ speed $)$.

at the inner race of bearing.

3) Dimple area density (DAD) played vital role in the performance of textured bearing. Among three considered DAD cases, 15\% DAD has yielded better tribo-dynamics.

4) Better retainability of the oil (base oil of the grease) 
Table 4 Summary of vibration magnitudes at different harmonics.

\begin{tabular}{|c|c|c|c|c|c|c|c|c|}
\hline \multirow[b]{2}{*}{ Bearing } & \multirow{2}{*}{$\begin{array}{l}\text { Load } \\
(\mathrm{N})\end{array}$} & \multirow[b]{2}{*}{$\begin{array}{l}\text { Speed } \\
(\mathrm{m} / \mathrm{s})\end{array}$} & \multicolumn{2}{|c|}{ Harmonic 1} & \multicolumn{2}{|c|}{ Harmonic 2} & \multicolumn{2}{|c|}{ Harmonic 3} \\
\hline & & & $\begin{array}{l}\text { Frequency } \\
(\mathrm{Hz})\end{array}$ & $\begin{array}{l}\text { Displacement } \\
(\mathrm{mm})\end{array}$ & $\begin{array}{l}\text { Frequency } \\
(\mathrm{Hz})\end{array}$ & $\begin{array}{l}\text { Displacement } \\
(\mathrm{mm})\end{array}$ & $\begin{array}{l}\text { Frequency } \\
(\mathrm{Hz})\end{array}$ & $\begin{array}{l}\text { Displacement } \\
(\mathrm{mm})\end{array}$ \\
\hline \multirow{12}{*}{$\begin{array}{c}\text { Conventional } \\
\text { (or un-textured } \\
\text { bearing) }\end{array}$} & \multirow{4}{*}{20} & 1.2 & 8.4 & 0.19 & 16.8 & 0.02 & 25.8 & 0.02 \\
\hline & & 2.0 & 13.4 & 0.19 & 26.8 & 0.03 & 40.0 & 0.01 \\
\hline & & 2.5 & 18.4 & 0.20 & 36.8 & 0.03 & 55.2 & 0.01 \\
\hline & & 3.4 & 23.4 & 0.14 & 46.8 & 0.03 & 72.2 & 0.02 \\
\hline & \multirow{4}{*}{40} & 1.2 & 8.4 & 0.18 & 16.6 & 0.02 & 25.0 & 0.01 \\
\hline & & 2.0 & 13.4 & 0.20 & 26.8 & 0.04 & 40.2 & 0.01 \\
\hline & & 2.5 & 18.4 & 0.20 & 36.6 & 0.02 & 55.0 & 0.01 \\
\hline & & 3.4 & 23.4 & 0.13 & 47.0 & 0.02 & 72.4 & 0.02 \\
\hline & \multirow{4}{*}{60} & 1.2 & 8.4 & 0.18 & 16.8 & 0.02 & 25.2 & 0.01 \\
\hline & & 2.0 & 13.4 & 0.16 & 26.6 & 0.04 & 40.0 & 0.03 \\
\hline & & 2.5 & 18.4 & 0.20 & 36.8 & 0.03 & 55.2 & 0.02 \\
\hline & & 3.4 & 23.4 & 0.12 & 46.8 & 0.04 & 72.4 & 0.02 \\
\hline \multirow{12}{*}{$\begin{array}{c}\text { Micro-textured } \\
\text { bearing with } \\
15 \% \text { DAD }\end{array}$} & \multirow{4}{*}{20} & 1.2 & 8.4 & 0.12 & 16.8 & 0.02 & 25.6 & 0.01 \\
\hline & & 2.0 & 13.4 & 0.13 & 26.8 & 0.02 & 40.8 & 0.02 \\
\hline & & 2.5 & 18.4 & 0.12 & 36.8 & 0.02 & 56.2 & 0.02 \\
\hline & & 3.4 & 23.4 & 0.11 & 46.2 & 0.02 & 70.8 & 0.01 \\
\hline & \multirow{4}{*}{40} & 1.2 & 8.4 & 0.16 & 16.8 & 0.03 & 25.6 & 0.02 \\
\hline & & 2.0 & 13.4 & 0.12 & 26.8 & 0.03 & 40.2 & 0.01 \\
\hline & & 2.5 & 18.4 & 0.12 & 37.0 & 0.02 & 56.6 & 0.01 \\
\hline & & 3.4 & 23.4 & 0.09 & 46.6 & 0.02 & 71.6 & 0.01 \\
\hline & \multirow{4}{*}{60} & 1.2 & 8.4 & 0.14 & 16.8 & 0.03 & 25.6 & 0.02 \\
\hline & & 2.0 & 13.4 & 0.11 & 26.6 & 0.02 & 40.8 & 0.02 \\
\hline & & 2.5 & 18.4 & 0.16 & 36.8 & 0.03 & 55.0 & 0.01 \\
\hline & & 3.4 & 23.4 & 0.10 & 46.6 & 0.03 & 71.6 & 0.02 \\
\hline
\end{tabular}

was found at textured inner race.

5) TEM micro-image revealed less damage of the grease soap fibers with textured bearing as compared to conventional case.

\section{Acknowledgements}

Authors acknowledge and thank the management of Indian Institute of Technology (IIT) Delhi for allowing to use the various experimental and measuring facilities. Moreover, the first author thanks the management of Osmania University, India, for sponsoring him to pursue his Ph.D. programme at IIT Delhi under quality improvement program (QIP) scheme.
Open Access This article is licensed under a Creative Commons Attribution 4.0 International License, which permits use, sharing, adaptation, distribution and reproduction in any medium or format, as long as you give appropriate credit to the original author(s) and the source, provide a link to the Creative Commons licence, and indicate if changes were made.

The images or other third party material in this article are included in the article's Creative Commons licence, unless indicated otherwise in a credit line to the material. If material is not included in the article's Creative Commons licence and your intended use is not permitted by statutory regulation or exceeds the permitted use, you will need to obtain permission 
directly from the copyright holder.

To view a copy of this licence, visit http://creativecommons.org/licenses/by/4.0/.

\section{References}

[1] Liu W, Ni H, Chen H, Wang P. Numerical simulation and experimental investigation on tribological performance of micro-dimples textured surface under hydrodynamic lubrication. Int J Mechl Sci 163: 1-12 (2019)

[2] Bhardwaj V, Pandey RK, Agarwal VK. Performance studies of textured race ball bearing. Ind Lubr Tribol 17: 11161123 (2019)

[3] Bhardwaj V, Pandey RK, Agarwal VK. Experimental investigations for tribo-dynamic behaviours of conventional and textured races ball bearings using fresh and $\mathrm{MoS}_{2}$ blended greases. Tribol Int 113: 149-168 (2017)

[4] Anandan N, Pandey R K, Jagga C R, Ghosh M K. Effects of starvation and viscous shear heating in hydrodynamically lubricated rolling/sliding line contacts. Proc Inst Mech Eng Part J J Eng Tribol 220: 535-547 (2006)

[5] Olaru D N, Gafitanu M D. Starvation in ball bearings. Wear 170: 219-234 (1993)

[6] Wikström V, Jacobson B. Loss of lubricant from oil-lubricated near-starved spherical roller bearings. Proc Inst Mech Eng Part J J Eng Tribol 211: 51-66 (1997)

[7] Gershuni L, Larson M G, Lugt P M. Lubricant replenishment in rolling bearing contacts. Tribol Trans 51: 643-651 (2008)

[8] Cen H, Lugt P M. Film thickness in a grease lubricated ball bearing. Tribol Int 134: 26-35 (2019)

[9] Xu M, Dai Q, Huang W, Wang X. Using magnetic fluids to improve the behavior of ball bearings under starved lubrication. Tribol Int 141: 1-6 (2020)

[10] Kundu P, Chopra S, Lad B K. Multiple failure behaviors identification and remaining useful life prediction of ball bearings. J Intell Manuf 30: 1795-1807 (2019)

[11] Mesgarnejad A, Khonsari MM. On the tribological behavior of $\mathrm{MoS}_{2}$ coated thrust ball bearings operating under oscillating motion. Wear 269: 547-556 (2010)

[12] Pinnock T, Voordouw J, Voordouw G. Use of carbon steel ball bearings to determine the effect of biocides and corrosion inhibitors on microbiologically influenced corrosion under flow conditions. Appl Microbiol Biotechnol 102: 57415751(2018)

[13] Tarasov S, Kolubaev A, Belyaev S, Lerner M, Tepper F. Study of friction reduction by nanocopper additives to motor oil. Wear 252: 63-79 (2002)
[14] Vanhulsel A, Velasco F, Jacobs R, Eersels L, Havermans D, Roberts E W, Sherrington I, Anderson M J, Gaillard L. DLC solid lubricant coatings on ball bearings for space applications. Tribol Int 40: 1186-1194 (2007)

[15] Marquart M, Wahl M, Emrich S, Zhang G, Sauer B, Kopnarski M, Wetzel B. Enhancing the lifetime of $\mathrm{MoS}_{2}$ lubricated ball bearings. Wear 303: 169-177 (2013)

[16] Mutyala K C, Singh H, Evans R D, Doll G L. Effect of diamond-like carbon coatings on ball bearing performance in normal, oil-starved, and debris-damaged conditions. Tribol Trans 59: 1039-1047 (2016)

[17] Zin V, Barison S, Agresti F, Colla L, Pagura C, Fabrizio M. Improved tribological and thermal properties of lubricants by graphene based nano-additives. RSC Adv 6: 59477-59486 (2016)

[18] Wang J, Zhao H, Huang W, Wang X. Investigation of porous polyimide lubricant retainers to improve the performance of rolling bearings under conditions of starved lubrication. Wear 381: 52-68 (2017)

[19] Gu J, Zhang Y, Liu H. Influences of wear on dynamic characteristics of angular contact ball bearings. Meccanica 54: 945-965 (2019)

[20] Sudeep U, Tandon N, Pandey R K. Performance of lubricated rolling/sliding concentrated contacts with surface textures: A review. J Tribol 137: 1-11 (2015)

[21] Gropper D, Wang L, Harvey T J. Hydrodynamic lubrication of textured surfaces: A review of modeling techniques and key findings. Tribol Int 94: 509-529 (2016)

[22] Gachot C, Rosenkranz A, Hsu S M, Costa H L. A critical assessment of surface texturing for friction and wear improvement. Wear 372-373: 21-41(2017)

[23] Sudeep U, Tandon N, Pandey R K. Vibration studies of lubricated textured point contacts of bearing steels due to surface topographies: simulations and experiments. Tribol Int 102: 265-274 (2016)

[24] Ai X, Cheng H S. The effects of surface texture on EHL point contacts. J Tribol 118: 59-66 (1996)

[25] Wang Q J, Zhu D. Virtual texturing: Modeling the performance of lubricated contacts of engineered surfaces. $J$ Tribol 127: 722-728 (2005)

[26] Mourier L, Mazuyer D, Lubrecht A A, Donnet C. Transient increase of film thickness in micro-textured EHL contacts. Tribol Int 39: 1745-1756 (2006)

[27] Ren N, Nanbu T, Yasuda Y, Zhu D, Wang Q. Micro textures in concentrated-conformal-contact lubrication: Effect of distribution patterns. Tribol Lett 28: 275-285 (2007)

[28] Organisciak M, Cavallaro G, Lubrecht A A. Variable lubricant supply of a starved hydrodynamic linear contact: 
Lubricant lateral flow for smooth and laser textured surfaces. Proc Inst Mech Eng Part-J J Eng Tribol 221: 247-258 (2007)

[29] Wang Q J, Zhu D, Zhou R, Hashimoto F. Investigating the effect of surface finish on mixed EHL in rolling and rollingsliding contacts. Tribol Trans 51: 748-761(2008)

[30] Nanbu T, Ren N, Yasuda Y, Zhu D, Wang Q J. Microtextures in concentrated conformal-contact lubrication: Effects of texture bottom shape and surface relative motion. Tribol Lett 29: 241-252 (2008)

[31] Zhu D, Nanbu T, Ren N, Yasuda Y, Wang Q J. Model-based virtual surface texturing for concentrated conformal-contact lubrication. Proc Inst Mech Eng Part J J Eng Tribol 224: 685-696 (2010)

[32] Gao L, Yang P, Dymond I, Fisher J, Jin Z. Effect of surface texturing on the elastohydrodynamic lubrication analysis of metal-on-metal hip implants. Tribol Int 43: 1851-1860 (2010)

[33] Podgornik B, Vilhena L M, Sedlacek M, Rek Z, Zun I. Effectiveness and design of surface texturing for different lubrication regimes. Meccanica 47: 1613-1622 (2012)

[34] Xu Y, Li Z, Zhang G, Wang G, Zeng Z, Wang C, Wang C, Zhao S, Zhang Y, Ren T. Electrochemical corrosion and anisotropic tribological properties of bioinspired hierarchical morphologies on $\mathrm{Ti}-6 \mathrm{Al}-4 \mathrm{~V}$ fabricated by laser texturing. Tribol Int 134: 352-364 (2019)

[35] Andersson P, Koskinen J, Varjus S, Gerbig Y, Haefke H, Georgiou S, Zhmud B, Buss W. Microlubrication effect by laser-textured steel surfaces. Wear 262: 369-379 (2007)

[36] Krupka I, Vrbka M, Hartl M. Effect of surface texturing on mixed lubricated non-conformal contacts. Tribol Int 41: 1063-1073 (2008)

[37] Vilhena L M, Sedlaček M, Podgornik B, Vižintin J, Babnik A, Možina J. Surface texturing by pulsed Nd:YAG laser. Tribol Int 42: 1496-1504 (2009)

[38] Gualtieri E, Borghi A, Calabri L, Pugno N, Valeri S. Increasing nanohardness and reducing friction of nitride steel by laser surface texturing. Tribol Int 42: 699-705 (2009)

[39] Hirayama T, Ikeda M, Suzuki T, Matsuoka T, Sawada H, Kawahara K. Effect of nanotexturing on increase in elastohydrodynamic lubrication oil film thickness. J Tribol 136: 1-3 (2014)

[40] Sudeep U, Tandon N, Pandey R K. Comparisons of tribological and vibration behaviors of textured point contacts of bearing steel lubricated with oil and grease under starved conditions. J Tribol 138: 1-12 (2016)

[41] Joshi G S, Putignano C, Gaudiuso C, Stark T, Kiedrowski T, Ancona A, Carbone G. Effects of the micro surface texturing in lubricated non-conformal point contacts. Tribol Int 127: 296-301 (2018)

[42] Sudeep U, Pandey R K, Tandon N. Effects of surface texturing on friction and vibration behaviors of sliding lubricated concentrated point contacts under linear reciprocating motion. Tribol Int 62: 198-207 (2013)

[43] Sudeep U, Tandon N, Pandey R K. Friction and vibration behaviors of lubricated laser textured point contacts under reciprocating rolling motion with highlights on the used laser parameters. Procedia Technol 14: 4-11 (2014)

[44] Sudeep U, Tandon N, Pandey R K. Tribological studies of lubricated laser-textured point contacts in rolling/sliding reciprocating motion with investigations of wettability and nano-hardness. Tribol Trans 58: 625-634 (2015)

[45] Chaudhary R, Pandey R K, Mazumdar S K. Tribological studies of low and high viscous oils lubricated heavily loaded textured point contacts under the reciprocating motion. Proc Inst Mech Eng Part J J Eng Tribol 234(2): 229-246 (2019)

[46] Zhai X, Chang L, Hoeprich M R, Nixon H P. On mechanisms of fatigue life enhancement by surface dents in heavily loaded rolling line contacts. Tribol Trans 40: 708-714 (1997)

[47] Vrbka M, Krupka I, Svoboda P, Sperka P, Navrat T, Hartl M, Nohava J. Effect of shot peening on rolling contact fatigue and lubricant film thickness within mixed lubricated non-conformal rolling/sliding contacts. Tribol Int 44: 1726-1735 (2011)

[48] Nakatsuji T, Mori A. The tribological effect of mechanically produced micro-dents by a micro diamond pyramid on medium carbon steel surfaces in rolling-sliding contact. Meccanica 36: 663-674 (2001)

[49] Epstein D, Keer L M, Wang Q J, Cheng H S. Effect of surface topography on contact fatigue in mixed lubrication. Tribol Trans 46: 506-513 (2003)

[50] Greco A, Martini A, Liu Y, Lin C, Wang Q J. Rolling contact fatigue performance of vibro-mechanical textured surfaces. Tribol Trans 53: 610-620 (2010)

[51] Samanek O, Zimmerman M, Svoboda P, Krupka I, Vrbka M. Influence of Surface texturing on lubricant film formation and surface fatigue. Eng Mech 17: 27-36 (2010)

[52] Vrbka M, Samanek O, Sperka P, Navrat T, Krupka I, Hartl M. Effect of surface texturing on rolling contact fatigue within mixed lubricated non-conformal rolling/sliding contacts. Tribol Int 43: 1457-1465 (2010)

[53] Vrbka M, Krupka I, Samanek O, Svoboda P, Vaverka M, Hartl M. Effect of surface texturing on lubrication film formation and rolling contact fatigue within mixed lubricated non-conformal contacts. Meccanica 46: 491-498 (2011) 


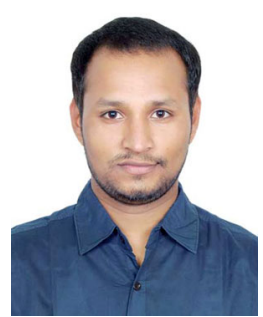

K. E. Ch. VIDYASAGAR. He received his B.Tech. \& M.Tech. (biomedical engineering) degrees from Jawaharlal Nehru Technological University (JNTU) Hyderabad, and Vellore Institute of Technology (VIT) Vellore,

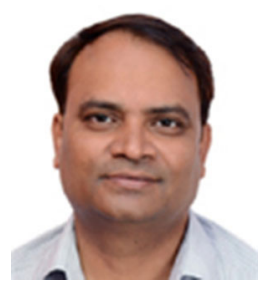

R. K. PANDEY. He received his B.E. \& M.E. (design of process equipments) degrees from National Institute of Technology (NIT). Allahabad, India, and Ph.D. (mechanical engineering) from IIT (Banaras Hindu University (BHU)), India. He joined

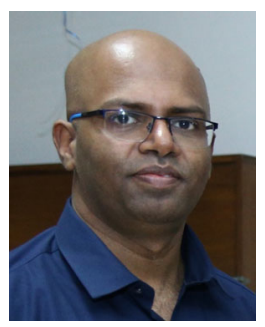

Dinesh KALYANASUNDARAM. He received his bachelor \& master degrees in mechanical engineering from College of Engineering, Guindy, Anna University and IIT Delhi, respectively. He received his Ph.D. (mechanical engineering) from Iowa
India, and pursuing Ph.D. (Centre for Biomedical Engineering) from IIT Delhi, India. He joined the Osmania University in 2014. His current position is assistant professor in Department of Biomedical Engineering. His research areas cover bio-tribology and laser based micromachining.

the IIT Delhi in 2002. His current position is professor in Department of Mechanical Engineering. His research areas cover machine design, fluid film and rolling bearings, lubrication, design of surfaces, and tribology of IC engines. Prior joining to IIT Delhi, he worked in industries.

State University, Ames, USA. He joined the IIT Delhi in 2013. He is currently an associate professor at Centre for Biomedical Engineering. His research areas cover design and development of manufacturing processes for medical devices. Prior joining to IIT Delhi, he worked in industries briefly. 